\title{
Approaches to the accounting of ecosystem services in the economic assessment of land degradation
}

\author{
E. V. Tsvetnov, O. A. Makarov, E. V. Bondarenko \\ \& Y. R. Ermiyaev \\ Laboratory of Economics of Land Degradation, \\ Lomonosov Moscow State University, Russia
}

\begin{abstract}
Degradation of soils causes degradation of the entire landscape and decreases the quality of human life. Economic evaluation of causes and consequences of soil degradation is very important for the creation of an optimal land management algorithm. Nowadays, we should include loss of a wide range of ecosystem (soil and land) services in the assessment of land degradation damage cost. Within the conducted research the scheme, allowing us to determine the entire possible range of soil services was proposed. Also the criteria for the selection of a sufficient set of services in each evaluation case were developed. It was suggested that there are 3 generalized criteria for economic interpretation of ecosystem services. It was shown that the damage calculated only on the basis of a recultivation budget is much lower than damage, which includes the valuation of lost ecosystem services. Keywords: soil, land degradation, ecosystem services.
\end{abstract}

\section{Introduction}

Today's reality is inconceivable without the prefix “eco". Eco-clean products, ecosecure energy, eco-friendly production, etc. This list is very long. Ecological challenges have gained in importance and have already become a topic of state policies.

Formulation of the concept of "ecosystem services" has a great impact on the implementation of environmental ideas. The understanding of the value of natural resources and the environment can dramatically change in the nearest future. 
Ecosystem services - are the benefits which people obtain from ecosystems [1]. The idea of ecosystem services is based on conception of natural capital. Natural capital is a set of assets of the environment. Using natural capital, means using services that are partly or fully provided by all components of the environment. There are four groups of such services [1-3]:

1) provisioning services (food, water, minerals, etc.);

2) protection services (carbon sequestration, waste decomposition and detoxification, disease control, etc.);

3) cultural services (aesthetic, recreational, scientific, educational, religious, etc.);

4) ecosystem supporting services (nutrient recycling, soil formation, etc.).

Thus, this conception was in the focus of our research. The main aim was to realize ecological and economic assessment of land degradation in the Russian Federation at local level, considering ecosystem services.

\section{Objects and methods}

\subsection{Methods}

\subsubsection{The selection and evaluation of ecosystem services}

At the first stage of our research we identified necessary and sufficient list of services for evaluation.

Soil services are derived from the functions performed by soil in nature. Soil releases a lot of functions in the environment, list of services corresponding to these functions is also wide [4]. Should we evaluate all of them? We offer the following statement (we use it as a rule): Despite the fact that all services can be evaluated, the purpose and objects' parameters put lot of limitations on the choice of ecosystem services for evaluation.

The purpose of the study is ecological and economic assessment of land degradation. So, range of services to be evaluated is narrow. We have to choose only those services that are changed in the process of agricultural land use.

To understand how the choice of the object affects the list of services for evaluation, we are to analyze the model of an agricultural land. Main assumptions are [5]:

1) soils of agricultural lands are transformed by mankind; 2) some part of the global and local functions of these soils does not realized or minimized as a result of such transformation; 3) from the ecocentric point of view, the negative effect of cultivation of natural systems is higher than benefit, so we can see the fact of degradation, but 4) in the case of agricultural lands, it would be rational to put utility for a man to the forefront, so we decided to accept the created agricultural soil, as an independent object, with no degradation and with its own (limited) set of functions.

So it will be wrong to evaluate ecosystem services of soils for agricultural purposes as the services of native soils.

Currently there is a wide range of methods helps us to evaluate ecosystem services [1-3, 6-8]. In general, it can be divided into seven blocks - market price 
method; travel cost method; hedonic price method; contingent valuation method; choice modeling method; methods based on the production function; methods based on the assessing the replacement cost of a "shadow infrastructure".

It is possible to formulate a number of general principles for the valuation of ecosystem services based on analysis of these methods [5].

1) The monetary evaluation of ecosystem services is carried out by searching of equivalent on the real market (within the conditions of local economy at the current time). All known methods of ecosystem services evaluation are suited to this statement. Mostly there are no independent markets of ecosystem services, so we have to model markets of ecosystem services equivalents. But if there the market of particular service exists, in such generalization it is possible to speak about full compliance with the equivalent.

Thus, we classified all mentioned methods by the criterion of market equivalent: the identification of full equivalent, the searching of service equivalent in the existing market, the analysis of "non-existent equivalent" (Figure 1).

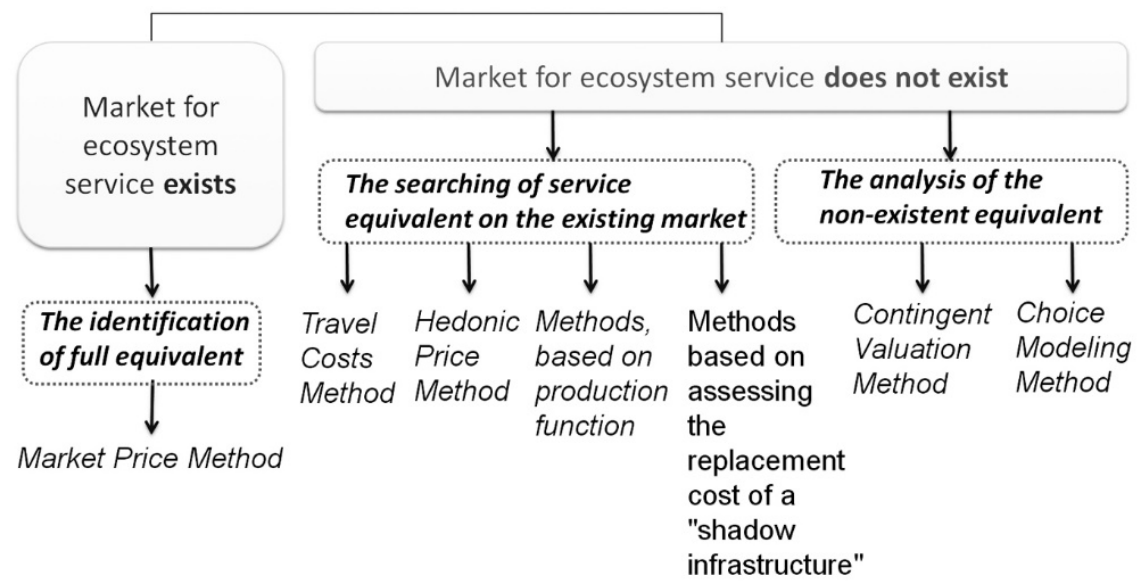

Figure 1: Classification of methods of ecosystem services evaluation, based on "market equivalent" criterion.

This generalization gives us some freedom of action at assessing ecosystem services (within the general rules of logic and the theory of estimation). We suggested that assessment should be simplify whenever it is possible. As it was mentioned, ecosystem services have no markets, so their evaluation is just reduction of overall uncertainty, but not estimation of absolute values. When particular markets for each service will be developed, there will be an opportunity to decline all approximate estimations.

2) The evaluation of ecosystem services is possible only if there is utility for land user.

3) In each case of evaluation, we have to determine the specific list of ecosystem services for evaluation. 


\subsubsection{The approaches of ecological economic evaluation of land degradation damage}

The damage caused by land degradation can be calculated by the formula (1) [9]:

$$
\text { Land degradation damage }=\text { Actual damage }+ \text { Loss of profit }
$$

\subsubsection{Actual damage determination}

Actual damage in case of land degradation problem is the cost of soil recultivation. The most effective way to calculate this cost - to summarize costs of realization different types of work, e.g. cleaning soils from pollutants, application of fertilizers and so on. Here we can use special computer programs, for example, SmetaWIZARD.

It is known that soil degradation is a set of processes that lead to change of soil functions as an element of the environment, quantitative and qualitative changes of soil properties and regimes, reduction of natural and economic importance of lands [10]. To calculate actual damage properly we have to access the degree and level as soil degradation.

According to accepted in Russia methods the degree of degradation of soils for each diagnostic criteria belongs to one of five levels: 1 - non-degraded; 2 - lowdegraded; 3 - medium-degraded; 4 - heavily-degraded; 5 - extremely-degraded, including the destruction of the soil cover.

To access the level of soil degradation, we compared soil properties of particular object with the standard soil, which properties corresponds to zero-level of loss of natural and economic importance of land.

\subsubsection{Loss of profit evaluation}

Loss of profit evaluation is often calculated by counting the losses from not receiving (or less receiving) of harvest of a particular crop as a result of land degradation. This approach significantly reduces the content of actual damage from land degradation, because in this case we have not only a decreasing of soil productivity, but also a violation of other soil and land services. We can transform formula (1) as follows:

\section{Land degradation damage $=$ Actual damage + Loss of profit $=$ $=$ The soil recultivation cost + Loss of ecosystem services}

\subsection{Characteristics of the object of study}

The ecological center of Moscow state University named "Chashnikovo", was the object of our study. It is located in the southern taiga (coniferous-deciduous forests subzone) close to Moscow. "Chashnikovo" is the base of summer studies of students and postgraduates of the soil science faculty. The center territory is mostly covered by Albeluvisols, all lands are classified as agricultural land. The total area is about 620 hectares.

During the summer 2014 on the territory of "Chashnikovo" were taken soil samples. Sampling was made on the analytical grid, size of each grid cell was 
$300 * 300$ meters. The different chemical and physico-chemical properties of the soils were determined: $\mathrm{pH}$, organic substance amounts, contents of phosphorus, potassium contents, amount of copper, lead, cadmium and zinc [8].

The main parameters of the degradation of "Chashnikovo" soils are the reduction of humus and nutrients, the decrease of soil $\mathrm{pH}$, and soil heavy metals pollution.

"Chashnikovo" soils mostly degraded by the content of exchange potassium and humus (Figure 2).

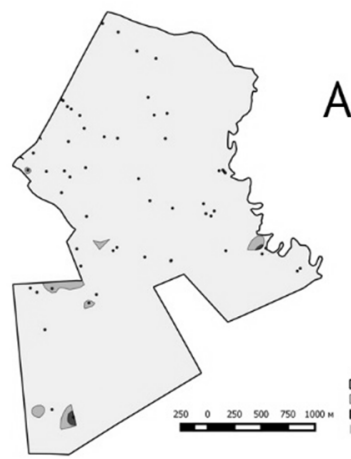

A

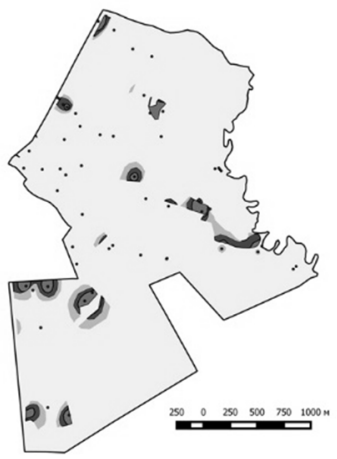

B
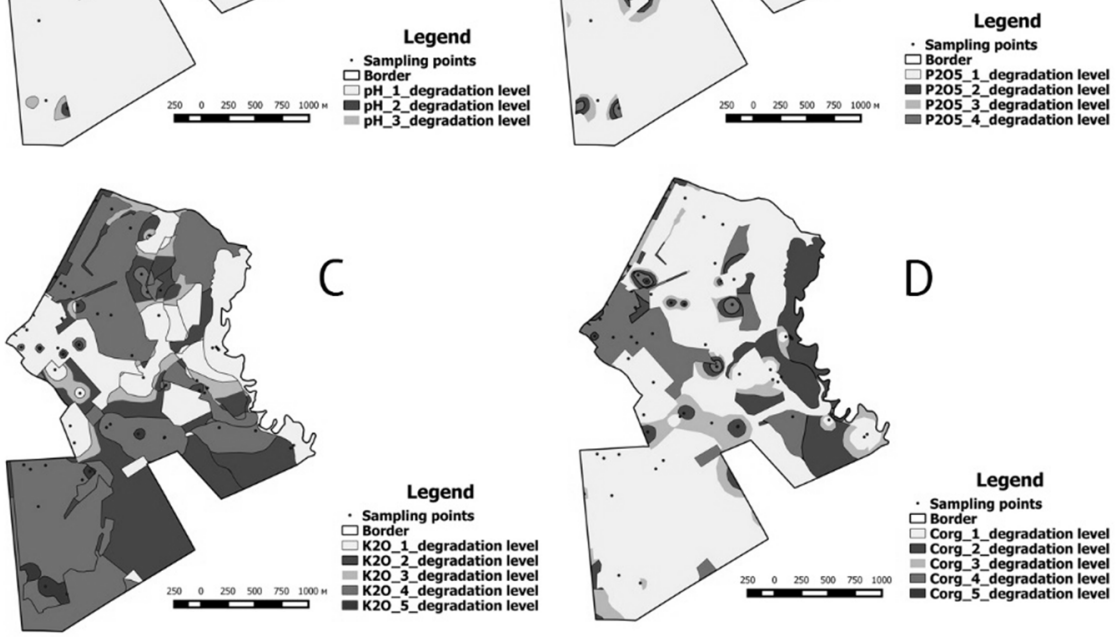

Figure 2: Schematic maps of soil degradation on Chashnikovo site: A) increase of acidity, B) decrease in the content of available phosphorus, C) decrease in exchangeable potassium, D) reduction of humus content.

In "Chashnikovo" soils, mainly close to the road and inhabited areas, occur high concentrations of cadmium, zinc and lead (Figure 3). 

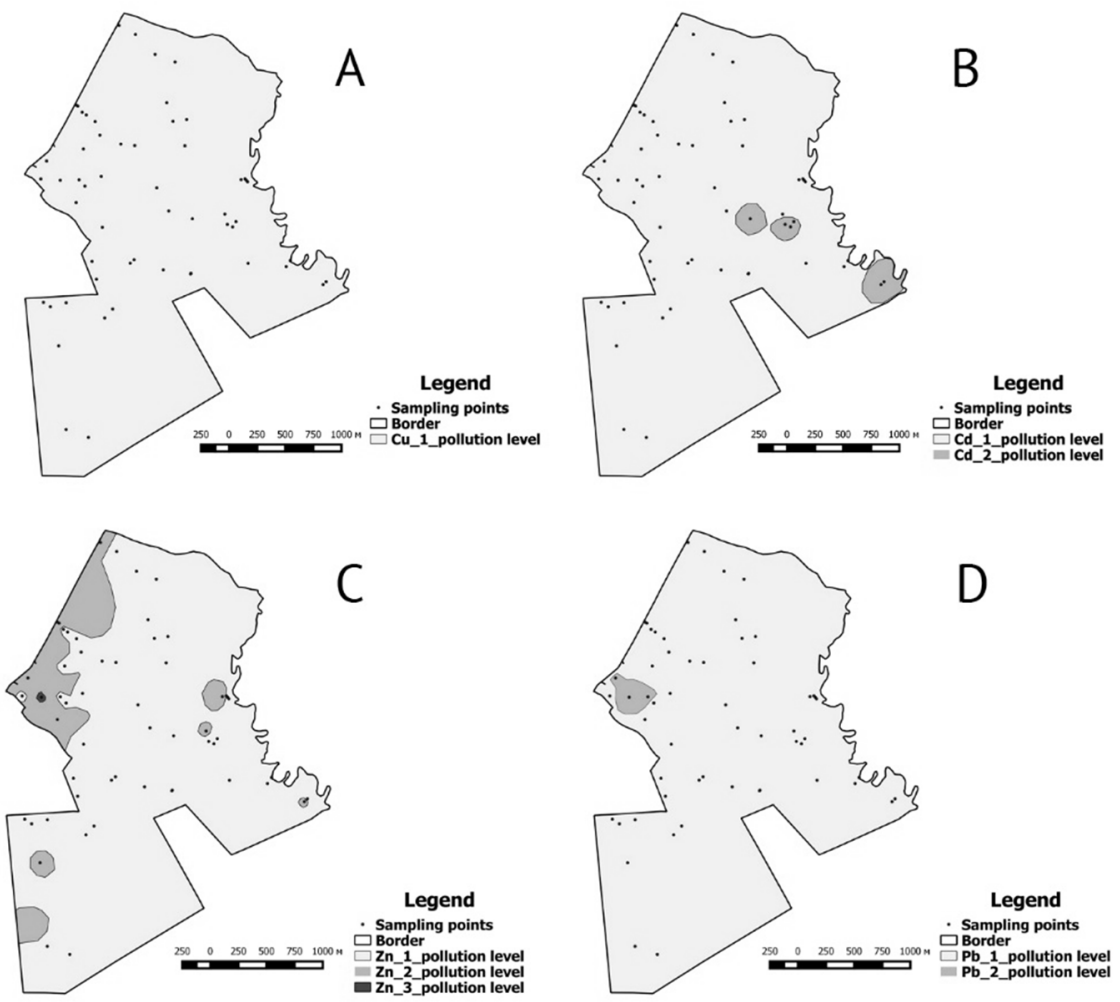

Figure 3: Schematic maps of soil heavy metal pollution on Chashnikovo site: A) $\mathrm{Cu}, \mathrm{B}) \mathrm{Cd}, \mathrm{C}) \mathrm{Zn}, \mathrm{D}) \mathrm{Pb}$.

\section{Results and discussion}

According to the formula (2) as a first step of evaluation we are to evaluate the cost of soil recultivation. The list of activities was proposed. It included two sections: 1) the remediation of polluted soils, 2) bringing the soil to the standard state by means of melioration. The recultivation cost for "Chashnikovo" soils is 1302 euro ไha.

The second stage of damage calculation was done by the loss of profit calculation. Three ecosystem services have been included: the loss of the direct provisioning of crops, loss of protection services and loss of cultural services (Figure 4). 


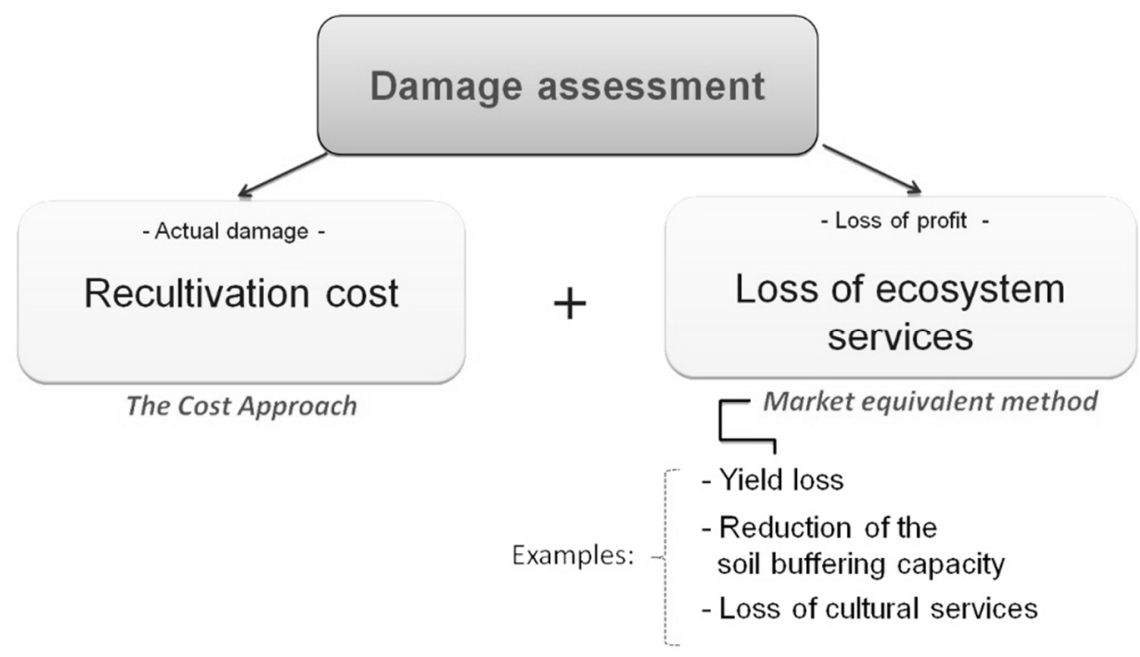

Figure 4: Schematic diagram of the calculation of the damage caused by land degradation in "Chashnikovo" site including ecosystem services.

\subsection{Land productivity loss}

Currently "Chashnikovo" soils are not used for agriculture. So, the crop losses are independent parameter of land degradation of this territory, associated with ineffective management.

To evaluate yields' losses we use regional statistics. The main parameters of estimation of provisioning service loss are:

- regional crop productivity,

- regional costs of agricultural production,

- regional prices of agricultural production.

Provisioning service loss for "Chashnikovo" site is 5857 euroไha.

It should be noted that non use of agricultural lands by their purpose is an actual problem for modern Russia.

\subsection{Protection service loss}

As already mentioned, on site was found heavy metals pollution, which allowed us to register the service of soil protection (from the negative effects of this type of pollution). It is reasonable to assume that excessive heavy metals pollution leads to increasing risk of morbidity.

For our purposes, it is important that a soil can reduce a damage caused by the pollution with heavy metals via transforming some of their amount into the forms unavailable for plants and, hence, for other links of the trophic chain, including humans. 
By inactivation of pollutants, soil reduces that risk. Thus, the more soil accumulates heavy metals, the stronger the quantitative characteristics of this service declines, so it degrades.

Soil tolerance toward chemical contamination is estimated from the buffer capacity of soil with respect to heavy metals. It can be determined according to the method suggested by Il'in [11, 12]. In this method, a conventional scale of the soil buffer capacity is applied. To develop such a scale, the contribution of the particular soil properties (the contents of humus, physical clay $(<0.01 \mathrm{~mm})$, sesquioxides, carbonates and the $\mathrm{pH}$ conditions) is estimated; then, these estimates are summed up. The behavior of different heavy metals in dependence on $\mathrm{pH}$ conditions is different: for most of them, the mobility of metals compounds decreases upon the soil alkalization; for some heavy metals (e.g., for Mo and As), it increases with the rise in $\mathrm{pH}$. Therefore, the estimates are given separately for the metals with an increased mobility in the acid medium and the metals with an increased mobility in the alkaline medium. A similar distinction is made in dependence on the presence of carbonates.

After these preliminary assessments, the buffer capacity is estimated from the sum of arbitrary points. Each degree of the total buffer capacity of soil with respect to heavy metals is characterized by its own range of hygienically acceptable levels of accumulation of heavy metals, i.e., those levels of potential contamination, upon which the obtained yield remains normatively clean.

As a result, parameters of estimation of protection service loss are:

- $\quad$ soil properties, associated with heavy metal pollution (V.B. ILiin's pointsystem estimation): Humus, $\mathrm{pH}$, sesquialteral oxides, soil clay, carbonates,

- buffering capacity of soil (hygienically acceptable number of background contents of heavy metals),

- heavy metal pollution in particular soil.

Protection service loss for "Chashnikovo" site is 1883 eurolha.

\subsection{Cultural services loss}

Another type of services, is educational services, part of the cultural services. We can identify the educational services here because of the fact that students and postgraduates of soil science faculty internship here in summer in a wide range of disciplines, with the necessity of field study of non-degraded (standart) soils. Soil degradation can lead to organization of educational tours outside "Chashnikovo" for studying non-degraded soils (the organizing cost of such tours is adequate economic interpreter required educational service).

The main parameters of estimation of cultural service loss are:

- cost of educational tours,

- the degree of differences (in soil properties and land use) between degraded and standard soil.

Protection service loss for "Chashnikovo" site is 148 eurotha.

Total calculation of land degradation damage on "Chashnikovo" site is presented in table 1. 
Table 1: Generalized evaluation of the degradation of ecosystem services.

\begin{tabular}{|c|c|}
\hline Damage parameter & Euro/ha \\
\hline \multicolumn{2}{|c|}{ Loss of ecosystem services (loss of profit) } \\
\hline Provisioning service loss & 5857 \\
\hline Protection service loss & 1883 \\
\hline Cultural services loss & 148 \\
\hline \multicolumn{2}{|c|}{ Recultivation cost (actual damage) } \\
\hline Recultivation cost & 1302 \\
\hline \multicolumn{2}{|c|}{ Total } \\
\hline
\end{tabular}

The table shows that the damage calculated only on the basis of recultivation budget is much lower than damage, which includes the valuation of lost ecosystem services.

\subsection{The practical significance of the proposed approaches}

- The majority of evaluations which take into account ecosystem services, are focused on undisturbed natural systems and are designed to obtain substantial economic arguments against including them in the economic use. The proposed method does not set any guidelines, showing that ecosystem services should be assessed similarly as for natural systems and as for systems anthropogenically modified. The main purpose of such inclusion in maintaining these systems in normal condition.

- Inclusion of ecosystem services in the economic assessment of land degradation is often used for the country-level or even continent-level and rarely for individual agricultural farms. But at the local level can be worked out the most effective strategy for counteraction land degradation processes.

- The method can be used as the basis for the formation of payments for the needs of sustainable land use (e.g., fines).

- Method transferred from land degradation problems on valuation in general, will be useful for the formation of ecological taxes. The usage of land value, which takes into account ecosystem services as the tax base will allow to generate a new system of environmental relations in society, to direct money flows in the channel of the balance of environment and economy (sustainable development).

\section{Conclusion}

1. Degradation of soil at the site of research has been identified for the following: increasing the acidity, reduction of humus content, available phosphorus, exchangeable potassium in comparison with the non- 
degraded analogues (standards). The highest value of degradation was found for the reduction of the exchangeable potassium and humus. Also in "Chashnikovo" soils, mainly close to the road, occur high concentrations of cadmium, zinc and lead.

2. Necessary and sufficient set of ecosystem services of soils of the research object were identified: the direct provision of crops, protection from negative effects of heavy metals pollution, cultural services (educational services). The total value of the loss of these ecosystem services on "Chashnikovo" site was 7888 eurolha (August 2015).

3. Accounting of soil and land ecosystem services should be an integral part of the ecological and economic evaluation of land degradation. In calculating the damage from land degradation should take into account the cost of the soil recultivation and the loss of specific list of ecosystem services. The damage calculated only on the basis of recultivation budget is much lower (1302 eurolha for "Chashnikovo" site) than damage, which includes the valuation of lost ecosystem services (9102 eurolha for "Chashnikovo" site).

\section{Acknowledgement}

The study was performed with a financial support of the Russian Science Foundation (project №14-38-00023).

\section{References}

[1] Millennium Ecosystem Assessment. Ecosystems and Human Well-being. Island Press: Washington, 2003.

[2] Perman R., Common M., Mcgilvray J. \& Ma Y., Natural Resource and Environmental Economics, Financial Times Press, 728 pp., 2003.

[3] Platon V., Frone S., \& Constantinescu A., New developments in assessing forest ecosystem services in Romania, Procedia Economics and Finance, 22, pp. 45-54, 2015.

[4] Dobrovolsky G.V. \& Nikitin, E.D., Soil ecology, MSU: Moscow, 413 pp., 2012 (in Russian).

[5] Tsvetnov E.V., Makarov O.A., Yakovlev A.S. \& Bondarenko E.V., On including of ecosystem services in land degradation damage evaluation, Soil science, 12., pp. 1-7, 2016 (in Russian).

[6] Bobylev, S.N. \& Khodzhaev, A.Sh., Economics of Nature Use, INFRA-M: Moscow, 501 pp., 2004 (in Russian).

[7] Bobylev, S.N. \& Zakharov, V.M., Ecosystem services and economics, Levko: Moscow, 79 pp., 2009 (in Russian).

[8] Bondarenko E.V., The experience of ecosystem services consideration in the evaluation of land degradation (on the example of MSU ecological center) Ph.D. (Biol.) Dissertation, Moscow State Univ: Moscow, 125 pp., 2016 (in Russian). 
[9] Medvedeva O.E. The evaluation of ecological damage in the process of land assessment, Property relations in the Russian Federation, 1, pp. 64-81, 2004 (in Russian).

[10] Methodological recommendations for identifying degraded and contaminated lands, Collection of normative acts "Protection of soil", Publishing house of the state Committee of environmental protection: Moscow, pp. 174-196, 1996 (in Russian).

[11] Il'in, V.B., Assessment of Soil Buffer Capacity toward Heavy Metals, Agrokhimiya, 10, pp. 109-113, 1995.

[12] Il'in, V.B., Buffering Properties of Soil and Its Permissible Level of Contamination with Heavy Metals, Agrokhimiya, 11, pp. 65-70, 1997. 